\title{
Combination of environmental stress and localization of L-asparaginase in Arthrospira platensis for production improvement
}

\author{
Asep A. Prihanto $\cdot$ Mamoru Wakayama
}

Received: 18 February 2014/ Accepted: 2 April 2014/Published online: 13 April 2014

(C) The Author(s) 2014. This article is published with open access at Springerlink.com

\begin{abstract}
The diverse applications of L-asparaginase have led us to explore new sources of this enzyme. Arthrospira platensis has been scarcely reported as a new candidate for L-asparaginase production. In the present study, we localized L-asparaginase in A. platensis and enhanced its production. Enzyme localization was conducted by culturing cells in SOT medium and extracting the enzymes from different parts of the cell. The Taguchi method (factors studied: nitrogen, iron, sodium chloride, and temperature shock) using an L9 orthogonal array was designed for improving L-asparaginase production. The highest specific activity of L-asparaginase was found in subcellular, cytoplasmic extracts $(0.166 \pm 0.029 \mathrm{U} / \mathrm{mg})$. Optimization data revealed that the highest production of L-asparaginase $(0.275 \pm 0.005 \mathrm{U})$ was attained by $\mathrm{NaNO}_{3}, \mathrm{NaCl}$, and $\mathrm{FeSO}_{4} \cdot 7 \mathrm{H}_{2} \mathrm{O}$ at concentrations, $1.875 \mathrm{~g} / \mathrm{l}, 0.25 \mathrm{M}$, and $0.0075 \mathrm{~g} / \mathrm{l}$, respectively, with 1 -h temperature shock at $22{ }^{\circ} \mathrm{C}$ in the dark. Results revealed more than twofold higher production of L-asparaginase than that under the normal condition. In summary, L-asparaginase appeared dominantly in the cytoplasmic region and its production could be induced by employing combined stress conditions with a Taguchi experimental design. To our best knowledge, this is the first report on L-asparaginase production in cyanobacteria of the subclass Oscillatoriophycideae.
\end{abstract}

Electronic supplementary material The online version of this article (doi:10.1007/s13205-014-0215-z) contains supplementary material, which is available to authorized users.

A. A. Prihanto $\cdot$ M. Wakayama ( $\square)$

Department of Biotechnology, Graduate School of Life Sciences,

Ritsumeikan University, 1-1-1 Nojihigashi, Kusatsu,

Shiga 525-8577, Japan

e-mail:wakayama@sk.ritsumei.ac.jp
Keywords Arthrospira platensis - Asparaginase - Stress · Production · Localization

\section{Introduction}

L-Asparaginase (L-asparagine amidohydrolase, EC 3.5.1.1) is an important enzyme that has applications in two main sectors: in medicine, the enzyme is used routinely for the treatment of acute lymphoblastic leukemia (Verma et al. 2007). Inhibition of leukemic cells results from depletion of the circulating pools of asparagine in the cell due to the hydrolysis of L-asparagine by L-asparaginase (ASNase). In food technology, ASNase is a potent mitigating agent for reducing the acrylamide contained in processed food. Acrylamide is suspected of being a carcinogen (Ciesarová et al. 2006; Hogervorst et al. 2008; Bongers et al. 2012).

ASNase is widely distributed among microorganisms. ASNase-derived microorganisms can cause anaphylactic shock and trigger the production of anti-ASNase antibodies when administered for a long term, yet they are still used in treatments. Erwinia carotovora, E. chrysanthemi, and Escherichia coli are well-known sources of ASNase (Mashburn and Wriston 1964; Pieters et al. 2011). Until now, ASNase derived from Aspergillus niger and A. oryzae is a well-known source for mitigating the effects of acrylamide because of its effectiveness and safety (Blumenthal 2004; Hendriksen et al. 2009).

Because of its potential in medicinal and food, research regarding microalgae has been conducted for a long time, and Arthrospira platensis may be the most studied microalgae. A. platensis is not only rich in nutrients but also contains several beneficial metabolites (Belay 2002). Currently, there is no specific report regarding production of ASNase in this blue-green microalga except for its 
proteomic data under temperature stress (Hongsthong et al. 2008; Kurdrid et al. 2011). Hence, the characterization and physiological roles of this enzyme in A. platensis had not been considered.

Optimization of ASNase production is important before industrial-scale production can be considered. Cells respond to environmental changes to ensure their survival. The medium and environmental conditions of the culture lead to modifications in cellular metabolism (Morgan-Kiss et al. 2006; Mosier et al. 2013). We hypothesized that ASNase can be expressed optimally in A. platensis under appropriate conditions. In addition, ascertaining the usability of ASNase from A. platensis in medical and foodtechnology applications is important.

Knowledge regarding the locations of ASNase is important to design an accurate extraction method as well as to confirm the role of this enzyme in A. platensis. In the present study, we investigated ASNase activity in all cell compartments. Furthermore, we investigated the appropriate culture conditions for optimizing ASNase production.

\section{Materials and methods}

\section{Reagents}

Nessler reagent was purchased from Nacalai Tesque (Kyoto, Japan). Trichloroacetic acid and Folin-Ciocalteu's phenol reagent were from Wako Pure Chemicals (Tokyo, Japan). The other reagents were chemically pure grades of commercial products.

\section{Strain and culture conditions}

A. platensis NIES-39 was grown in standard SOT medium with slight modification (Ogawa and Terui 1970). The composition of the medium was as follows: $16.8 \mathrm{~g} / \mathrm{l}$ $\mathrm{NaHCO}_{3}, 0.5 \mathrm{~g} / \mathrm{l} \mathrm{K}_{2} \mathrm{HPO}_{4}, 2.5 \mathrm{~g} / 1 \mathrm{NaNO}_{3}, 1 \mathrm{~g} / \mathrm{l} \mathrm{K}_{2} \mathrm{SO}_{4}$, $1 \mathrm{~g} / \mathrm{l} \mathrm{NaCl}, 0.2 \mathrm{~g} / \mathrm{l} \mathrm{MgSO} \cdot 7 \mathrm{H}_{2} \mathrm{O}, 0.04 \mathrm{~g} / \mathrm{l} \mathrm{CaCl}_{2} \cdot 2 \mathrm{H}_{2} \mathrm{O}$, $0.01 \mathrm{~g} / \mathrm{l} \quad \mathrm{FeSO}_{4} \cdot 7 \mathrm{H}_{2} \mathrm{O}, \quad 0.08 \mathrm{~g} / \mathrm{l} \quad \mathrm{Na}_{2}$ EDTA, $0.03 \mathrm{mg} / \mathrm{l}$ $\mathrm{H}_{3} \mathrm{BO}_{3}, 0.025 \mathrm{mg} / \mathrm{l} \quad \mathrm{MnSO}_{4} \cdot 7 \mathrm{H}_{2} \mathrm{O}, 0.002 \mathrm{mg} / \mathrm{l} \mathrm{ZnSO}_{4}$. $7 \mathrm{H}_{2} \mathrm{O}, 0.0079 \mathrm{mg} / \mathrm{l} \mathrm{CuSO} \cdot 5 \mathrm{H}_{2} \mathrm{O}, 0.0021 \mathrm{mg} / \mathrm{l} \mathrm{Na} \mathrm{MoO}_{4}$. $2 \mathrm{H}_{2} \mathrm{O}$ in distilled water with additional $1 \mathrm{ml}$ micronutrients $\left(2.86 \mathrm{~g} / 1 \mathrm{H}_{3} \mathrm{BO}_{3}, 2.5 \mathrm{~g} / \mathrm{l} \mathrm{MnSO}_{4} \cdot 7 \mathrm{H}_{2} \mathrm{O}, 0.22 \mathrm{~g} / 1 \mathrm{ZnSO}_{4}\right.$. $7 \mathrm{H}_{2} \mathrm{O}, 0.079 \mathrm{~g} / 1 \mathrm{Na}_{2} \mathrm{Mo}_{4} \cdot 2 \mathrm{H}_{2} \mathrm{O}$ ). Cells were cultured in a $500 \mathrm{ml}$ Erlenmeyer flask containing $200 \mathrm{ml}$ medium with reciprocal shaking at $150 \mathrm{rpm}$ and $30{ }^{\circ} \mathrm{C}$. The flask was illuminated by fluorescent white lamps providing a total intensity of approximately $130 \mu \mathrm{mol}$ photons $\mathrm{m}^{-2} \mathrm{~s}^{-1}$. Cells were harvested in the mid-logarithmic phase of growth $\left(\mathrm{OD}_{730}=1.00\right)$.
Table 1 Condition of stress factors and its level in Taguchi method design

\begin{tabular}{lllll}
\hline No. & Factor & Level 1 & Level 2 & Level 3 \\
\hline 1 & Nitrogen (\%) & 25 & 50 & 75 \\
2 & $\mathrm{NaCl}(\mathrm{M})$ & 0.25 & 0.50 & 0.75 \\
3 & $\mathrm{Fe} \mathrm{( \% )}$ & 25 & 50 & 75 \\
4 & $T$ duration (h) & 1 & 2 & 3 \\
\hline
\end{tabular}

Duration of dark temperature stress ( $T$ duration) was set up on the basis of the incubation time after temperature shift by referring to the report (Deshnium et al. 2000)

\section{Enzyme extraction}

Cells were passed through filter paper for separation of cells from the medium. The medium was used as the ASNase-extracellular fraction (A). To extract the enzyme in different locations of the cell, the method described by Necinova et al. 1974 was modified and used. Filtrated cells were washed with $10 \mathrm{mM}$ potassium phosphate buffer $(\mathrm{KPB})$ at $\mathrm{pH} 7$, resuspended in $8 \mathrm{ml}$ buffer and mixed directly with the solution for periplasmic extraction $(4 \mathrm{ml}$ of $40 \%$ sucrose, $8 \mathrm{ml}$ of $10 \mathrm{mM} \mathrm{KPB}$ at $\mathrm{pH} 7$ and $2 \mathrm{ml}$ of $0.8 \mathrm{mg} / \mathrm{ml}$ of lysozyme). The suspension was incubated for $25 \mathrm{~min}$ at $30^{\circ} \mathrm{C}$ with gentle agitation. Further, $8 \mathrm{ml}$ of $10 \mathrm{mM} \mathrm{KPB}(\mathrm{pH} 7)$ and $2 \mathrm{ml}$ of EDTA $(18 \mathrm{mg} / \mathrm{ml})$ were added to the suspension. The suspension was incubated further at $30{ }^{\circ} \mathrm{C}$ with gentle agitation for $40 \mathrm{~min}$. To obtain a periplasmic sample (B), the solution was centrifuged at $10,000 \mathrm{rpm}$ for $20 \mathrm{~min}$ to procure the supernatant. To the pellet, which contained spheroplasts and remaining cells, $12 \mathrm{ml}$ of ice-cold water was added. Before centrifugation of the solution for $20 \mathrm{~min}$ at $10,000 \mathrm{rpm}$ at $4{ }^{\circ} \mathrm{C}$, the suspension was incubated for $10 \mathrm{~min}$ in ice-cold water with reciprocal shaking. Supernatant I was collected and the centrifugation procedure was repeated for the pellet to procure supernatant II. Supernatants I and II were combined and centrifuged for $30 \mathrm{~min}$ at $12,000 \mathrm{rpm}$ at $4{ }^{\circ} \mathrm{C}$. The obtained supernatant was the cytoplasmic sample (C). To the pellet, which contained the cell membrane, $10 \mathrm{ml}$ of $10 \mathrm{mM}$ KPB (pH 7) was added. The suspension was centrifuged at $12,000 \mathrm{rpm}$ for $30 \mathrm{~min}$ at $4{ }^{\circ} \mathrm{C}$. A membranebound preparation (D) was obtained by the addition of $4 \mathrm{ml}$ of $10 \mathrm{mM} \mathrm{KPB}$ (pH 7) to the pellet.

Taguchi experimental design

The stress conditions affecting the enzyme yield were optimized by the Taguchi method using an L9 orthogonal array. The factors studied in this study consist of nitrogen $(\mathrm{N})$, iron $(\mathrm{Fe})$, and sodium chloride $(\mathrm{NaCl})$ along with temperature stress at $22{ }^{\circ} \mathrm{C}$ in dark for varied duration 
Table 2 Taguchi's experimental design using L9 $(3 \times 4)$ orthogonal array

\begin{tabular}{llllll}
\hline Exp & \multicolumn{3}{l}{ Factor no. } & & Production (U)* \\
\cline { 2 - 5 } & 1 & 2 & 3 & 4 & \\
\hline 1 & 1 & 1 & 1 & 1 & $0.091 \pm 0.004$ \\
2 & 1 & 2 & 2 & 2 & $0.011 \pm 0.027$ \\
3 & 1 & 3 & 3 & 3 & $0.018 \pm 0.007$ \\
4 & 2 & 1 & 2 & 3 & $0.117 \pm 0.037$ \\
5 & 2 & 2 & 3 & 1 & $0.063 \pm 0.020$ \\
6 & 2 & 3 & 1 & 2 & $0.072 \pm 0.039$ \\
7 & 3 & 1 & 3 & 2 & $0.177 \pm 0.007$ \\
8 & 3 & 2 & 1 & 3 & $0.081 \pm 0.008$ \\
9 & 3 & 3 & 2 & 1 & $0.130 \pm 0.041$ \\
Validation & 3 & 1 & 3 & 1 & $0.275 \pm 0.005$ \\
\hline
\end{tabular}

The number (1, 2 and 3 ) below each factor no. (1-4) indicates the level of each factor described in Table 1

* The values represent the mean $\pm \operatorname{SE}(n=3)$

$(1,2$, and $3 \mathrm{~h})$. This temperature was applied to give enough stress, but still allowed A. platensis to grow. $\mathrm{N}$ and Fe stresses were conducted by reducing the content of $\mathrm{NaNO}_{3}$ and $\mathrm{FeSO}_{4} \cdot 7 \mathrm{H}_{2} \mathrm{O}$ from the original amount. $\mathrm{NaCl}$ stress was implemented by increasing the concentration of $\mathrm{NaCl}$ in standard SOT medium. Dark temperature stress was initiated after growth reached an optical density at $730 \mathrm{~nm}\left(\mathrm{OD}_{730}\right)$ of $0.8-1.2$ at $30^{\circ} \mathrm{C}$. The layout of the $\mathrm{L} 9$ orthogonal array as well as levels of the factors studied is presented in Tables 1 and 2. All calculations and analyses were performed using Qualitek-4 software (NUTEK Inc. USA). The effect of these factors was analyzed on the basis of the signal-to-noise ratio $(\mathrm{S} / \mathrm{N})$.

Protein and ASNase assay

Proteins were assayed using the Lowry method using egg albumin as a standard (Lowry et al. 1951). ASNase activity was measured by the Nessler method (Imada et al. 1973). A mixture of $150 \mu \mathrm{l}$ of crude enzyme, $50 \mu \mathrm{l}$ of $1 \mathrm{M} \mathrm{KPB} \mathrm{(pH} \mathrm{7),} 200 \mu \mathrm{l}$ of deionized-water, and $100 \mu \mathrm{l}$ of $150 \mathrm{mM} \mathrm{L}$-asparagine was incubated for $30 \mathrm{~min}$ at $30{ }^{\circ} \mathrm{C}$. To the reaction mixture, was added $125 \mu \mathrm{l}$ of $20 \%$ trichloroacetic acid (TCA) to terminate the reaction. The mixture was then centrifuged at $2,000 \mathrm{rpm}$ for $15 \mathrm{~min}$. To the $450 \mu \mathrm{l}$ of pipetted supernatant, $125 \mu \mathrm{l}$ of the Nessler solution was added. The solution was maintained for $15 \mathrm{~min}$ to allow the appropriate reaction between the Nessler solution and ammonia. The results were obtained at $\mathrm{OD}_{480} \mathrm{~nm}$. One unit of enzymatic activity was defined as $1 \mu \mathrm{mol}$ of ammonia per minute under described condition.

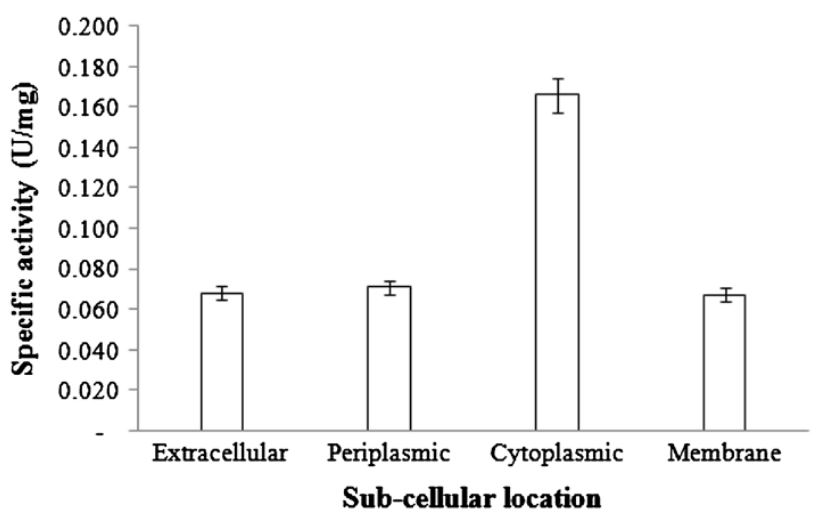

Fig. 1 Subcellular L-asparaginase activity of A. platensis NIES-39. The values represent the mean $\pm \operatorname{SE}(n=3)$

\section{Results}

Distribution of ASNase

We examined the distribution of ASNase in A. platensis cells by measuring its enzymatic activity. Enzyme activity was detected in all parts of the cell. The calculated enzymespecific activity was $0.067 \pm 0.004-0.166 \pm 0.029 \mathrm{U} / \mathrm{mg}$. Extracellular, periplasmic fluid and membrane-bound extracts did not exhibited high ASNase-specific activity (Fig. 1). In contrast, the cytoplasmic extract exhibited high specific activity $(0.166 \pm 0.029 \mathrm{U} / \mathrm{mg})$. Extracellular samples contained high protein content, and they exhibited similar specific activity to that of periplasmic and membrane-bound extracts.

Individual factors affecting ASNase production

Optimization of production by combined stress was expressed as total enzyme activity. The preliminary culture condition using standard SOT medium at $30^{\circ} \mathrm{C}$ did not produce a high yield of ASNase, with a yield of only $0.127 \mathrm{U}$ noted in the cytoplasmic region. Several modifications with regard to the content of SOT medium and culture conditions were employed to trigger high production of ASNase in A. platensis. Our data revealed that these cells responded to the combination of factors in different ways (Table 2), whereas the individual factors examined suggested different effects on ASNase production (Table 3; Fig. 2).

The impact, variation, and contribution of each individual selected factor were assessed by analysis of variance (ANOVA). The calculated $F$-ratio suggested that all parameters were significant at 95 and $99 \%$ confidence intervals. Among all selected factors, $\mathrm{N}$ maximally affected ASNase production $(55.40 \%)$, followed by $\mathrm{NaCl}$ $(28.13 \%)$. Fe had a minor contribution in ASNase 
Table 3 Analysis of variance (ANOVA)

\begin{tabular}{llcccccc}
\hline$\#$ & Interaction factor & DOF $(f)$ & Sum of square $(\mathrm{S})$ & Variance $(\mathrm{V})$ & $F$-ratio $(\mathrm{F})$ & Pure sum $\left(\mathrm{S}^{\prime}\right)$ & Percent P $(\%)$ \\
\hline 1 & Nitrogen & 2 & 0.025 & 0.012 & 252.893 & 0.025 & 55.405 \\
2 & $\mathrm{NaCl}$ & 2 & 0.012 & 0.110 & 128.904 & 0.012 & 28.133 \\
3 & Iron & 2 & 0.001 & 0 & 17.624 & 0.001 & 3.658 \\
4 & Duration temp & 2 & 0.005 & 0.002 & 50.711 & 0.004 & 10.934 \\
& Error & 9 & -0.001 & -0.001 & & 1.872 \\
& Total & 17 & 0.045 & & & 100.00 \\
\hline
\end{tabular}
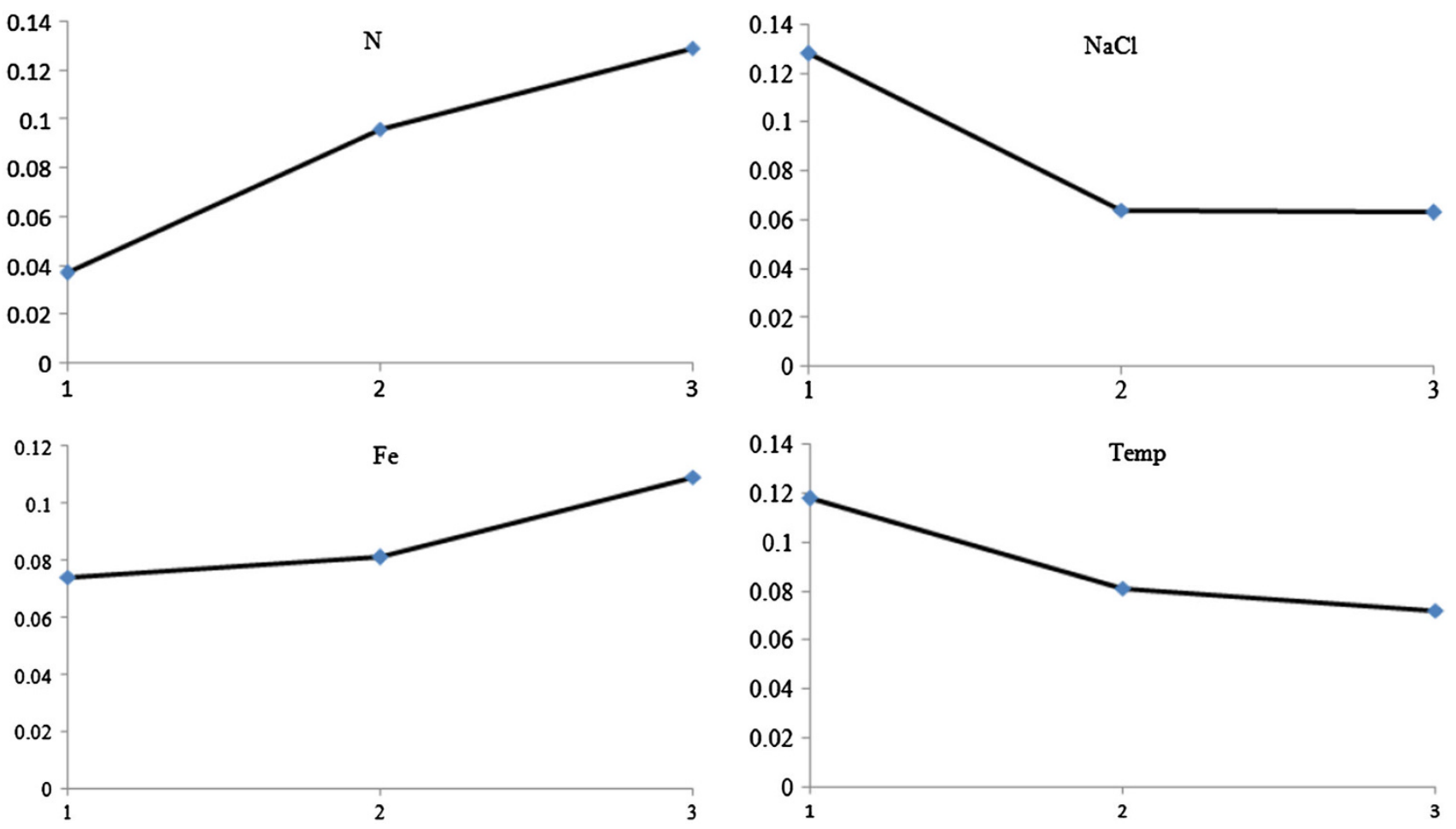

Fig. 2 Impact of each factor to A. platensis ASNase production. The horizontal axis represents the experimental factor level. The vertical axis represents the ASNase production expressed in total activity (unit)

production $(3.65 \%)$. In this study, $83.53 \%$ contribution was achieved with only $\mathrm{N}$ and $\mathrm{NaCl}$ stress factors. These data suggested that $\mathrm{N}$ and $\mathrm{NaCl}$ played an important role in ASNase production in A. platensis.

$\mathrm{N}$ noticeably affected the enzyme production. High amount of $\mathrm{N}$ in the medium generated the higher ASNase yield (Fig. 2). The highest production of ASNase (0.129 U) was obtained using $75 \% \mathrm{~N}$. In contrast, Fe modification had little effect upon ASNase production. A low amount of $\mathrm{Fe}$ in the medium failed to elicit a noteworthy impact. SOT medium containing only $25-75 \%$ Fe yielded almost similar results with regard to ASNase production. All modification of $\mathrm{Fe}$ contents generated ASNase in the range 0.085-0.011 U (Fig. 2).

High $\mathrm{NaCl}$ content in the medium positively affected the yield of ASNase. A. platensis cells exhibited exhilarating responses when experiencing high sodium stress compared with the $0.017 \mathrm{M} \mathrm{NaCl}$ found in standard SOT medium. SOT medium containing $0.25 \mathrm{M} \mathrm{NaCl}$ was optimal with regard to the amount of $\mathrm{NaCl}$ in the medium for eliciting high production of ASNase (0.132 U). However, an excess of $\mathrm{NaCl}$ resulted in decreased production of ASNase. ASNase productions in A. platensis were the same at $0.5 \mathrm{M}$ of $\mathrm{NaCl}$ and $0.75 \mathrm{M}$ of $\mathrm{NaCl}$ (highest concentration).

The duration of temperature stress followed the same trend as that observed for $\mathrm{NaCl}$ experimental data. Incubating cultures at $22{ }^{\circ} \mathrm{C}$ for $1 \mathrm{~h}$ elicited the best results for ASNase production $(0.117 \mathrm{U})$. In contrast, subjecting $A$. platensis cells for $2 \mathrm{~h}$ in temperature stress conditions decreased ASNase production, with the lowest production (0.065 U) observed for 3-h temperature stress. Longer durations of temperature stress resulted in further decrease 
Table 4 Severity Index of DOE

\begin{tabular}{llllll}
\hline$\#$ & $\begin{array}{l}\text { Interaction factor pairs } \\
\text { (order based on SI) }\end{array}$ & Columns & SI $(\%)$ & Col & Opt \\
\hline 1 & NaCl $\times$ duration temp & $2 \times 4$ & 58.13 & 6 & {$[1,2]$} \\
2 & Nitrogen $\times$ iron & $1 \times 3$ & 37.49 & 2 & {$[3,3]$} \\
3 & Iron $\times$ duration temp & $3 \times 4$ & 30.27 & 7 & {$[3,2]$} \\
4 & NaCl $\times$ iron & $2 \times 3$ & 29.06 & 1 & {$[1,3]$} \\
5 & Nitrogen $\times \mathrm{NaCl}$ & $1 \times 2$ & 23.79 & 3 & {$[3,1]$} \\
6 & Nitrogen $\times$ duration & $1 \times 4$ & 10.09 & 5 & {$[3,2]$} \\
& temp & & & & \\
\hline
\end{tabular}

Table 5 Optimal condition and their performance in ASNase production

\begin{tabular}{llll}
\hline Factor & Level description & Level & Contribution* \\
\hline Nitrogen (\%) & 75 & 3 & 0.039 \\
$\mathrm{NaCl}(\mathrm{M})$ & 0.25 & 1 & 0.037 \\
$\mathrm{Fe}(\%)$ & 75 & 3 & 0.013 \\
$T$ duration (h) & 1 & 1 & 0.022 \\
Total contribution from all factor & & 0.11 \\
Current grand average performance & & 0.09 \\
Expected result at optimum conditions & & 0.20 \\
\hline
\end{tabular}

* The values are expressed as total activity (unit)

in ASNase production. Consequently, the influence of each factor, including $\mathrm{N}, \mathrm{NaCl}$, duration of temperature stress, and Fe stress, on ASNase production was found to be 55.4, $28.1,10.9$, and $3.6 \%$, respectively (Table 3 ).

Interaction and optimization of factors in ASNase production

The Taguchi method using the L9 orthogonal array, enabled the analysis of the influence of each factor and its interaction. In addition, the optimum condition for producing ASNase could be readily ascertained using the Qualitek-4 software. In the Taguchi method, the interaction of individual factors was estimated using the perceived severity index (SI) value. The analyses assisted to provide better understanding of the overall ASNase production process in A. platensis. The interaction of $\mathrm{NaCl}$ and duration of temperature stress represented the highest SI value of $58.13 \%$. In fact, Fe depletion exhibited the least significant effect upon ASNase production (3.6\%), when combined with $\mathrm{N}$ stress; thus, contributing to the second highest SI (37.49\%, Table 4). These data revealed that interactions of parameters could have different effects on ASNase production compared with individual parameters.

The predicted optimum condition for high production of ASNase in A. platensis was examined using modified SOT medium containing $75 \% \mathrm{~N}\left(1.875 \mathrm{~g} / 1 \mathrm{NaNO}_{3}\right), 0.25 \mathrm{M}$
$\mathrm{NaCl}, 75 \% \mathrm{Fe}\left(0.0075 \mathrm{~g} / \mathrm{l} \mathrm{FeSO} \cdot \cdot 7 \mathrm{H}_{2} \mathrm{O}\right)$, and 1-h temperature stress in dark. The total contribution from all factors was $0.11 \mathrm{U}$. In this condition, the expected production of ASNase was $0.20 \mathrm{U}$ (Table 5).

\section{Validation of selected factors}

Experimental validation of our prediction using SOT stress medium containing $75 \% \mathrm{~N}, 0.25 \mathrm{M} \mathrm{NaCl}, 75 \% \mathrm{Fe}$ with 1-h duration in dark and temperature stresses was conducted. The maximum amount of ASNase production $(0.275 \pm 0.005 \mathrm{U})$ was achieved under this condition (Table 2). The obtained value was higher than the predicted production (0.20 U, Table 5). Furthermore, ASNase production was approximately 2.17 -fold greater than that compared with production by culturing A. platensis in standard SOT medium at $30{ }^{\circ} \mathrm{C}$ in the absence of temperature stress.

\section{Discussion}

To examine the location of ASNase in A. platensis cells, ASNase activities in extracellular and subcellular fractions were measured. ASNase activities were observed in several locations, with the highest specific activity being exhibited in cytoplasmic extracts $(0.166 \pm 0.029 \mathrm{U} / \mathrm{mg})$. A. platensis NIES-39 contains two genes encoding putative ASNase, designated with entry names of NIES39_A07830 and NIES39_E04380 in the KEGG (Kyoto Encyclopedia of Genes and Genomes) data base (http://www.genome.jp). On the basis of the nucleotides sequence data, we analyzed the subcellular location of ASNase using an online server for prediction of enzyme location (Yu et al. 2006, 2010; Magnus et al. 2012). The result of analysis was presented in supplementary material 1 . The CELLO subcellular localization predictor system predicted that both ASNases were in the cytoplasmic area. Furthermore, MetaLocGramN analyses suggested that both ASNases were expressed in the cytoplasmic area with 65-85\% degrees of confidence. pSORTb predicted that both enzymes were in the cytoplasmic area and that existence of these enzymes in other regions was also possible, but only in minor amounts.

The relatively large amount of protein in the extracellular fraction was probably because of the liberation of intracellular proteins. Moreover, liberation of cytoplasmic proteins probably occurred in dead cells during culture and excessively harsh agitation during A. platensis culture. Agitation during culture can affect the integrity of cell membranes, particularly non-covalent protein interactions in cell membranes; therefore, they become "leaky", and can result in release of cytoplasmic proteins, including ASNase (Mader 2000). 
Stress cultures are the proven methods for altering the physiological and biochemical behaviors of cyanobacteria (Allen et al. 2005; Sundaram and Soumya 2011). Therefore, such cultures can elicit metabolism modifications in A. platensis. In the normal SOT medium, A. platensis produced low cytoplasmic ASNase $(0.127 \pm 0.107 \mathrm{U})$. Hence, we modified the SOT medium and culture condition to provide stress to optimize cytoplasmic ASNase production.

In cyanobacteria, nitrogen and iron have a vital role with respect to its photosynthesis (Bauer et al. 1993) and their stresses induce the synthesis of several proteins (Fernandes et al. 1993; Kolodny et al. 2006). Effect of salt stress on growth and photosynthesis of A. platensis was reported (Vonshak et al. 1988). Since light is essential to photosynthesis in A. platensis, treatment of A. platensis under the dark condition in a definite period of time is expected to produce an effect on carbon and nitrogen metabolism in $A$. platensis. Temperature is also one of the stress factors affecting the physiological and biochemical changes in $A$. platensis. It has been reported that the expression level and mRNA stabilization of desD gene in A. platensis were enhanced by a temperature shift from 35 to $22{ }^{\circ} \mathrm{C}$ (Deshnium et al. 2000). On the ground of these previous studies, we chose four factors, $\mathrm{N}, \mathrm{Fe}, \mathrm{NaCl}$, and dark low temperature as stress factors in this study.

We found that a lack of $\mathrm{N}$ and $\mathrm{Fe}$ at early stages of growth reduced ASNase production. This result suggested a strong association between $\mathrm{N}$ and $\mathrm{Fe}$ and ASNase production. An abundance of $\mathrm{N}$ in cyanobacteria cells is reserved in proteins found in cyanophycin granules (multiL-arginyl-poly-L-aspartic acid). A lack of $\mathrm{N}$ will decrease the amount of cyanophycin because $\mathrm{N}$ is the vital compound in cyanophycin synthesis (Picossi et al. 2004). This phenomenon was confirmed by Allen et al. 1980, who revealed that $\mathrm{N}$ deficiency decreases cyanophycin in the cytoplasm. The low yield of ASNase was probably because of low cyanophycin content in the cell. However, a large amount of $\mathrm{N}\left(100 \%\right.$ of $\left.\mathrm{NaNO}_{3}\right)$ resulted in low ASNase production in SOT normal medium. Hence, $\mathrm{N}$ must be available in the medium in sufficient quantities for its usage in cyanophycin and ASNase production.

The other consequence of insufficient amount of $\mathrm{N}$ and $\mathrm{Fe}$ includes interference in photosynthesis because of abnormal pigments. A. platensis cells at all treatments exhibited less green color compared with A. platensis cells grown in normal SOT medium (unpublished data). A sign of the development of atypical pigments was indicated by color changes in the cell cultures from green to yellowish. Bleaching of color pigments in cell cultures is a sign of nutrient depletion, particularly $\mathrm{N}$ content, which is because of a change in pigment color called "chlorosis" (Collier and Grossman 1992; Sauer et al. 2001). This is followed by a lack of energy supply in the cell because of interferences in photosynthesis. The lacks of iron hampered a complete function of photosynthetic machinery in cyanobacteria including reduced levels of chlorophyll, phycocyanin, phycobilisomes, ferredoxin, flavodoxin and other essential photosynthetic electron transport (Sandmann and Malkin 1983; Sandmann et al. 1990; Ferreira and Straus 1994). Fe stress appeared to induce an energy insufficient condition in the cell throughout the interference in photosynthesis. Exposure of cyanobacteria to high salinity correlated with its time of transition from lag to log phase, demanding higher energy for growth (Vonshak et al. 1988). Cyanobacteria degrade cyanophycin when they require energy. Bacteria exploit cyanophycin for growth and energy because it is abundant reserved source of $\mathrm{N}$, carbon, and energy (Obst et al. 2005). Furthermore, dark environment and lack of energy would trigger A. platensis to provide sufficient energy to maintain its metabolism.

Degradation of cyanophycin, which provides an abundance of polypeptides during lack of energy, appeared to cause an effective enhancement of ASNase production. Cyanophycin was degraded in the dark condition where no energy source was supplied. Cyanophycin would be degraded to $\beta$-asp-Arg, the main substrate for plant-type ASNase (Richer et al. 1999). It can be inferred that plentiful amounts of $\beta$-asp-Arg in the cytoplasm would boost the ASNase production and that $\beta$-asp-Arg could be used as an "ASNase inducer".

In this study, using a Taguchi experimental design, we enhanced ASNase production of the ASNase by approximately 2.17 -fold $(0.275 \pm 0.005 \mathrm{U})$ compared with production using standard SOT medium with a normal culture $(0.127 \pm 0.107 \mathrm{U})$. Further research regarding exploration of more efficient production, purification, characterization and application of the enzyme is needed.

In conclusion, high specific activity of ASNase was found in the cytoplasmic region. Depletion of $\mathrm{N}$ and $\mathrm{Fe}$ negatively affected ASNase production. $\mathrm{NaCl}$ and temperature shock in the dark condition may have contributed to ASNase production because of energy generation through cyanophycin degradation. The link between several experimental factors (Table 3) led us to a new hypothesis that ASNase production is probably induced by multiple factors. We here revealed that combined stresses could be applied to optimize ASNase production in A. platensis.

Acknowledgments A. platensis NIES-39 was kindly provided by Dr. Kazuki Terauchi. The first author is grateful to Directorate General of Higher Education (DGHE), Ministry of Education and Culture, Republic of Indonesia, for financial support.

Conflict of interest The authors declare that they have no conflict of interest in the publication. 
Open Access This article is distributed under the terms of the Creative Commons Attribution License which permits any use, distribution, and reproduction in any medium, provided the original author(s) and the source are credited.

\section{References}

Allen MM, Hutchison F, Weathers PJ (1980) Cyanophycin granule polypeptide formation and degradation in the cyanobacterium Aphanocapsa 6308. J Bacteriol 141:687-693

Allen MM, Yuen CM, Medeiros L, Zizlsperger N et al (2005) Effects of light and chloramphenicol stress on incorporation of nitrogen into cyanophycin in Synechocystis sp. strain PCC 6308. Biochim Biophys Acta 1725:241-246

Bauer CC, Scappino L, Haselkorn B (1993) Plant biology growth of the cyanobacterium anabaena on molecular nitrogen: NifJ is required when iron is limited. Proc Natl Acad Sci 90:8812-8816

Belay A (2002) The potential application of Spirulina (arthrospira) as a nutritional and therapeutic supplement in health management. JANA 5:26-48

Blumenthal CZ (2004) Production of toxic metabolites in Aspergillus niger, Aspergillus oryzae, and Trichoderma reesei: justification of mycotoxin testing in food grade enzyme preparations derived from the three fungi. Regul Toxicol Pharmacol 39:214-228

Bongers ML, Hogervorst JGF, Schouten LJ, Goldbohm RA et al (2012) Dietary acrylamide intake and the risk of lymphatic malignancies: the Netherlands cohort study on diet and cancer. PLoS One 7:e38016

Ciesarová Z, Kiss E, Boegl P (2006) Impact of L-asparaginase on acrylamide content in potato products. J Food Nutr Res 45:141-146

Collier JL, Grossman AR (1992) Chlorosis Induced by Nutrient Deprivation in Synechococcus sp. Strain PCC 7942: not all bleaching is the same. J Bacteriol 174:4718-4726

Deshnium P, Paithoonrangsarid K, Suphatrakul A, Meesapyodsuk D et al (2000) Temperature-independent and -dependent expression of desaturase genes in filamentous cyanobacterium Spirulina platensis strain C1 (Arthrospira sp. PCC9438). FEMS Microbiol Lett 184:207-213

Fernandes TA, Iyer V, Apte SK (1993) Differential responses of nitrogen-fixing cyanobacteria to salinity and osmotic stresses. Appl Environ Microbiol 59:899-904

Ferreira F, Straus NA (1994) Iron deprivation in cyanobacteria. J Appl Phycol 6:199-210

Hendriksen HV, Kornbrust BA, Østergaard PR, Stringer MA (2009) Evaluating the potential for enzymatic acrylamide mitigation in a range of food products using an asparaginase from Aspergillus oryzae. J Agric Food Chem 57:4168-4176

Hogervorst JG, Schouten LJ, Konings EJ, Goldbohm RA et al (2008) Dietary acrylamide intake and the risk of renal cell, bladder, and prostate cancer. Am J Clin Nutr 87:1428-1438

Hongsthong A, Sirijuntarut M, Prommeenate P, Lertladaluck K et al (2008) Proteome analysis at the subcellular level of the cyanobacterium Spirulina platensis in response to low-temperature stress conditions. FEMS Microbiol Lett 288:92-101

Imada A, Igarasi S, Nakahama K, Isona M (1973) Asparaginase and glutaminase activities of microorganisms. J Gen Microbiol 76:85-99

Kolodny NH, Bauer D, Bryce K, Klucevsek K et al (2006) Effect of nitrogen source on cyanophycin synthesis in Synechocystis sp. strain PCC 6308. J Bacteriol 188:934-940

Kurdrid P, Senachak J, Sirijuntarut M, Yutthanasirikul R et al (2011) Comparative analysis of the Spirulina platensis subcellular proteome in response to low- and high-temperature stresses: uncovering cross-talk of signaling components. Prot Sci 9:1-17

Lowry OH, Rosebrough NJ, Farr AL, Randall RJ (1951) Protein measurement with the folin phenol reagent. J Biol Chem 193:265-275

Mader SS (2000) Inguiry into life, 9th edn. McGraw-Hill, Boston

Magnus M, Pawlowski M, Bujnicki JM (2012) MetaLocGramN: a meta-predictor of protein subcellular localization for gramnegative bacteria. Biochim Biophys Acta 1824:1425-1433

Mashburn LT, Wriston JC (1964) Tumor inhibitory effect of Lasparaginase from Escherichia coli. Arch Biochem Biophys 105:450-452

Morgan-Kiss RM, Priscu JC, Pocock P, Gudynaite-Savitch L et al (2006) Adaptation and acclimation of photosynthetic microorganisms to permanently cold environments. Microbiol Mol Biol Rev 70:222-252

Mosier AC, Justice N, Bowen B, Baran BP et al (2013) Metabolites associated with adaptation of microorganisms to an acidophilic, metal-rich environment identified by stable-isotope-enabled metabolomics. MBio 4:1-9

Necinova SS, Svobodova O, Vranova J (1974) Localization of Lasparaginase in Escherichia coli. Folia Microbiol 19:474-478

Obst M, Krug A, Luftmann H, Steinbuchel A (2005) Degradation of cyanophycin by Sedimentibacter hongkongensis strain KI and Citrobacter amalonaticus strain $\mathrm{G}$ isolated from an anaerobic bacterial consortium. Appl Environ Microbiol 71:3642-3652

Ogawa T, Terui G (1970) Studies on the growth of Spirulina platensis. (I) on the pure culture of Spirulina platensis. J Ferment Technol 48:361-367

Picossi S, Valladares A, Flores E, Herrero A (2004) Nitrogenregulated genes for the metabolism of cyanophycin, a bacterial nitrogen reserve polymer. J Biol Chem 279:11582-11592

Pieters R, Hunger SP, Boss J, Rizzari C et al (2011) L-Asparaginase treatment in acute lymphoblastic leukemia: a focus on Erwinia asparaginase. Cancer 117:238-249

Richer R, Hejazi M, Kraft R, Ziegler K et al (1999) Cyanophycin, a peptidase degrading the cyanobacterial reserve material multy-Larginyl-poly-L-aspartic acid (cyanophycin). Molecular cloning of the gene of Synechocystis sp. PCC 6803, expression in Escherichia coli and biochemical characterization of the purified enzyme. Eur J Biochem 263:163-169

Sandmann G, Malkin R (1983) Iron-sulfur centers and activities of the photosynthetic electron transport chain in iron-deficient cultures of the blue-green alga Aphanocapsa. Plant Physiol 73:724-728

Sandmann G, Peleato ML, Fillat MF, Lazaro MC, Gomez-Moreno C (1990) Consequences of iron-dependent formation of ferredoxin and flavodoxin on photosynthesis and nitrogen fixation on Anabaena strains. Photosynth Res 26:119-125

Sauer J, Schreiber U, Schmid R, Volker U et al (2001) Nitrogen starvation-induced chlorosis in Synechococcus PCC 7942. Lowlevel photosynthesis as a mechanism of long-term survival. Plant Physiol 126:233-243

Sundaram S, Soumya KK (2011) Study of physiological and biochemical alteration in cyanobacterium under organic stress. Am J Plant Physiol 6:1-16

Verma N, Kumar K, Kaur G, Anand S (2007) L-Asparaginase: a promising chemotherapeutic agent. Crit Rev Biotechnol 27:45-62

Vonshak A, Guy R, Guy M (1988) The response of the filamentous cyanobacterium Spirulina platensis to salt stress. Arch Microbiol 150:417-420

Yu CS, Chen YC, Lu CH, Hwang JK (2006) Prediction of protein subcellular localization. Proteins 64:643-651

Yu NY, Wagner JR, Laird MR, Melli G et al (2010) PSORTb 3.0: improved protein subcellular localization prediction with refined localization subcategories and predictive capabilities for all prokaryotes. Bioinforma 26:1608-1615 